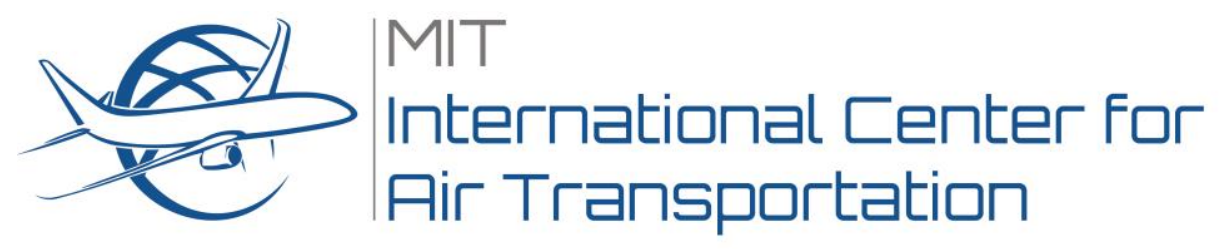

\title{
EVALUATION OF KEY OPERATIONAL CONSTRAINTS AFFECTING ON-DEMAND MOBILITY FOR AVIATION IN THE LOS ANGELES BASIN: GROUND INFRASTRUCTURE, AIR TRAFFIC CONTROL AND NOISE
}

\author{
Parker D. Vascik and R. John Hansman
}

This report presents research originally published under the same title at the $17^{\text {th }}$ AIAA Aviation Technology, Integration, and Operations Conference in Denver, CO. Citations should be made to the original work with DOI: 10.2514/6.2017-3084.

Report No. ICAT-2017-10

June 2017

MIT International Center for Air Transportation (ICAT)

Department of Aeronautics \& Astronautics

Massachusetts Institute of Technology

Cambridge, MA 02139 USA 


\title{
Evaluation of Key Operational Constraints Affecting On-Demand Mobility for Aviation in the Los Angeles Basin: Ground Infrastructure, Air Traffic Control and Noise
}

\author{
Parker D. Vascik ${ }^{1}$ and R. John Hansman ${ }^{2}$ \\ Massachusetts Institute of Technology, Cambridge, Massachusetts, 02139
}

\begin{abstract}
This paper investigated three key operational constraints anticipated to impact OnDemand Mobility for Aviation markets in the Los Angeles basin including: community acceptance issues resulting from aircraft noise, the availability of takeoff and landing areas, and the scalability of operations under Air Traffic Control. The analysis provided insight into the nature of each of these constraints and potential approaches to their mitigation. First, existing ground infrastructure in Los Angeles that may support ODM Aviation operations was identified. A variety of proposed techniques to increase the geographic distribution and throughput capacity of ODM Aviation infrastructure were also evaluated. Second, ASDE-X radar tracking data from the Los Angeles International Airport was reviewed to identify areas where it may be feasible to route future ODM operations due to the low volume of conventional operations. Potential opportunities and risks associated with supplementing air traffic control through novel low-altitude management concepts such as NASA's Unmanned Aircraft System Traffic Management (UTM) program were also investigated. Finally, the influence of aircraft noise on local communities' acceptance of aircraft operations was discussed. Various pathways through which communities may limit or prohibit aircraft operations were reviewed.
\end{abstract}

\section{Introduction}

$\mathrm{O}$ N-Demand Mobility (ODM) for Aviation refers to an emerging transportation concept that promotes multimodal, point to point transportation within a metropolitan area utilizing networks of novel vertical takeoff and landing (VTOL) aircraft for the central leg of the mission. ODM Aviation may provide numerous benefits to consumers and cities including diversified mobility options, an expanded mobility reach of economic basins, added resiliency to a city's transportation networks, and a means to overcome highway congestion [1].

Previous studies concerning ODM Aviation have focused primarily on assessing the technical feasibility of electric aircraft and verifying the market opportunities [2]-[4]. To address a perceived literature gap in systems-level operational analysis, this research explicitly identified the set of operational constraints facing ODM Aviation networks and assessed how new vehicles and technologies may mitigate or reduce the severity of these constraints. A companion publication to this paper, available as Ref. [5], presented a case study conducted in Los Angeles that conducted an exploratory analysis of potential network operations to identify a set of five operational constraints and three issues that may influence the near or far-term implementation of ODM Aviation. Figure 1 displays the five identified operational constraints showing the notional dependence of their severity (degree of operational restriction) as a function of the density (number of operations) of an ODM network in a metropolitan area.

This paper picks up where the previous companion paper left off by reviewing the top three prioritized operational constraints in greater detail and exploring a variety of approaches to lessen or overcome their impact on ODM Aviation operations. The three key constraints are those which were projected to have the most severe impacts upon the operation of ODM Aviation networks and have been listed below with their key properties:

\footnotetext{
${ }^{1}$ Ph.D. Candidate, ICAT, MIT, 77 Massachusetts Avenue, 33-115, Student Member, AIAA.

${ }^{2}$ Professor of Aeronautics and Astronautics, MIT, 77 Massachusetts Avenue, 33-303, AIAA Fellow. 


\section{Availability of Takeoff and Landing Areas (TOLAs)}

- The average distance from the customer origin point to the nearest current aviation infrastructure in the 12 reference missions was three miles

- Some suburban regions were found not have existing aviation infrastructure within 10 miles

- The lack of TOLAs amplifies aircraft staging, congestion and route capacity challenges

- The development and use of new TOLA infrastructure is dependent upon approval from the municipal governments and landowners

- TOLAs located in residential areas may expose operators to nuisance or government takings lawsuits from nearby landowners disturbed by the operations

\section{Scalability of ODM Networks Under Air Traffic Control}

- Over $40 \%$ of urban and suburban Los Angeles resides within a surface-level controlled airspace

- Eleven of the twelve reference missions required entrance into a surface-level controlled airspace

- A high density of ODM Aviation operations may overload ATC capabilities, reduce or eliminate aircraft throughput, and create interaction issues with helicopters, aircraft and UAS in controlled airspace

\section{Aircraft Noise and Community Acceptance}

- TOLAs are likely to be located within urban and suburban areas bringing aircraft operations in closer proximity to people than experienced at current airports

- Aircraft noise may make ODM operations susceptible to nuisance or government takings lawsuits

- Aircraft noise may restrict access to TOLAs in specific geographic areas or during certain times of day

In addition to burdening ODM Aviation operations with varying levels of restrictions as a function of network scale, flight location, time of day and weather conditions, among other factors, these three operational challenges also differ in the difficulty or expense with which they may potentially be mitigated. For example, the availability of TOLAs in metropolitan areas may be as simple to mitigate as developing more facilities or expanding existing facility capacity in high demand areas. However, assuring ODM aircraft have reliable access to

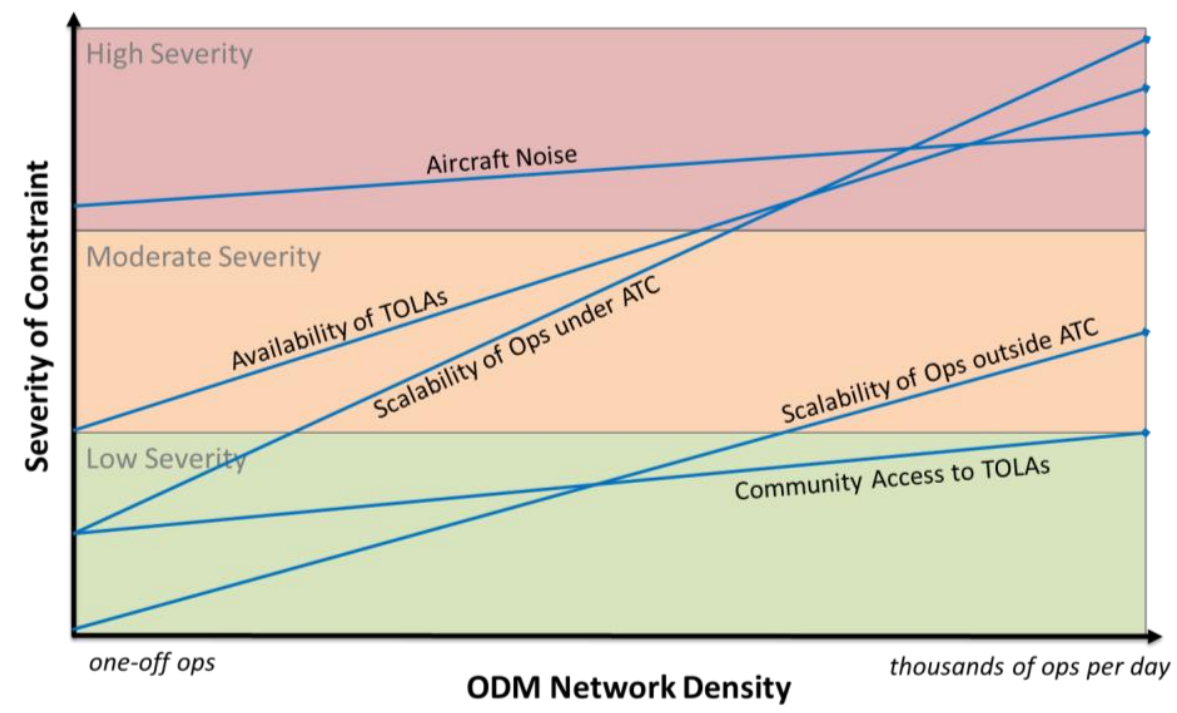

Figure 1. Notional dependence of ODM constraints on network density.

ATC controlled airspace, on the other hand, could involve non-trivial changes to ATC procedures, staffing, technologies or even regulations.

Through a series of workshops, publications and research programs, the ODM Aviation community, the FAA and NASA have proposed a variety of mitigation approaches to address many of the constraints identified through this research. However, a comprehensive review of the feasibility of these mitigation approaches and their impact on the entire ODM Aviation network has not been conducted.

Therefore, this paper reviews how the implementation of a variety of proposed mitigation approaches may potentially address the three prioritized constraints. The near-term implementability of each mitigation proposal was first evaluated for a small-scale ODM Aviation network. The influence of the mitigation approach on the network was assessed, and the degree to which it may lessen or remove the constraint was considered. Furthermore, ancillary effects of the mitigation approach on each of the other constraints (perhaps beneficial or detrimental) were investigated. Finally, the capacity of the mitigation technique to scale with increasingly dense ODM networks and operations (a far-term consideration) was investigated. 
The research presented in this paper may be considered the initial phase of developing a system architecting plan for ODM Aviation. This analysis identified the most prevalent near-term constraints and explored if proposed mitigation approaches were sufficient to support the implementation of early adopter ODM Aviation services. The analysis then continued with far-term planning through an investigation of approaches to mitigate the constraints that become binding as an ODM network grows in scale. Ideally, the ODM community and regulators may adopt a mature system architecting plan to direct investments to develop key technologies and mitigation approaches. Such a coordinated plan could minimize investments in constraints that are not currently binding on operations while directing strategic, proactive investments to resolve constraints that may otherwise become severe in the far-term.

\section{Evaluation of the Availability of Takeoff and Landing Areas}

In order for a public or commercial metropolitan-area transportation mode to become competitive with the personal automobile, the service must provide customers with sufficient geographic coverage of a region to enable relatively easy access to a core set of desired destinations. Automobiles currently enjoy a high geographic coverage that provides customers with door to door service between nearly any two locations. Current public transportation modes, such as buses or subways, typically operate as a lattice network that crisscrosses a metropolitan region providing reasonable geographic coverage to specific corridors and communities. Current aircraft and helicopter operations, however, typically have a very low geographic coverage as they primarily operate from a limited set of ground infrastructure nodes (airports or helipads).

A limited set of mobility network nodes (TOLAs, for example) located in key areas of demand may be sufficient to support a sustainable transportation network, albeit with limited growth potential. The heliports in Manhattan are a prime example of such a network. Three high capacity heliports, all located on the waterfront, support a network of helicopter operators ferrying individuals to and from New York's three major airports; these heliports also support a large tourism industry. If the goal of ODM Aviation is not to just serve a few high-demand routes or corridors, but rather to become a ubiquitous form of transportation, then a network of geographically well-distributed TOLAs is essential.

The review conducted in this section identified numerous proposed mitigation techniques that have the potential to significantly increase the availability of TOLAs. However, significant challenges were found to exist for the implementation of the mitigation techniques including aircraft performance, regulatory, community acceptance and business challenges. New technologies, especially electric aviation, show promise to reduce or overcome some of these challenges, however others remain largely unaddressed at this time. Aircraft noise, an ODM Aviation constraint in its own right, is of particular importance to TOLA availability as it heavily influences community acceptance and regulatory compliance.

TOLA availability represents a classic "chicken and egg" conundrum. ODM Aviation networks can only attract and service a large base of customers once a geographically distributed set of TOLAs is implemented with sufficient capacity. However, the financing and market acceptance of a geographically distributed set of TOLAs may only emerge once the benefits of ODM Aviation are widely acknowledged through the successful implementation of these services. Recognizing this challenge, ODM operators may benefit from beginning services along specific routes or corridors with limited infrastructure requirements to gain experience and build positive public sentiment. Additionally, investors or businesses with geographically diverse storefronts or real estate holdings may capture entire new markets by investing in TOLA development and certification in order to lease access to the emerging ODM operators.

\section{A. Existing Aviation Ground Infrastructure in Los Angeles}

Los Angeles was selected as the focus of the initial ODM Aviation case study due in part to the large number of airports and helipads that already exist in the region. The FAA reported in 2013 that Los Angeles County alone had 27 airports and 138 registered heliports, with numerous unregistered emergency helicopter landing facilities spread throughout the region [6]. With this level of built infrastructure, Los Angeles has more improved TOLAs than any city in the United States, and perhaps any city in the world. Yet, despite this marked benefit, the review of the reference missions in Ref. [5] concluded the geographic coverage of TOLAs in Los Angeles was insufficient to support widespread ODM Aviation operations.

To better identify the current availability of TOLAs in Los Angeles, a study was conducted to identify all of the airports and helipads in the area including both registered and unregistered facilities. First, the FAA 5010 database, Helicopter Association International heliport directory and AirNav.com databases were interrogated to collect the location and type (private, public, EMS heliport or airport) of TOLAs included in these resources. Second, a visual scan was conducted of the Los Angeles metropolitan area in Google Earth to identify existing aviation ground 
infrastructure. The review identified a total of 310 existing helipad or airport facilities within roughly 37 nmi of the Los Angeles International Airport. Table I displays the breakdown of these TOLAs by type.

Interestingly, while Los Angeles hosts a large number of existing TOLAs, $70 \%$ of the facilities are Emergency Helicopter Landing Facilities (EHLFs). An EHLF is a helipad that is not certified for use by the FAA and is only intended to be used for emergency purposes. The design of an EHLF is dictated by local ordinance and may vary from municipality to municipality. Los Angeles County has an extensive number of EHLFs because $\$ 57.4705 .4$ of the local municipality code required any building of 75 feet or greater built after 1974 to have either a FAA certified helipad or an EHLF on the roof [7]. While the Los Angeles Fire Department Requirement Number 10 was updated in 2014 to no longer require a high-rise rooftop helipad [8], the built infrastructure will remain within the county for decades to come.

Figure 2 displays the geographic location of all 310 TOLAs in the Los Angeles metropolitan area. The color of the "pin" marker indicates the type of facility. As may be seen in the figure, the helipads in Los Angeles are not geographically well-distributed and tend to be aggregated in the central business districts (CBDs). This trend is most

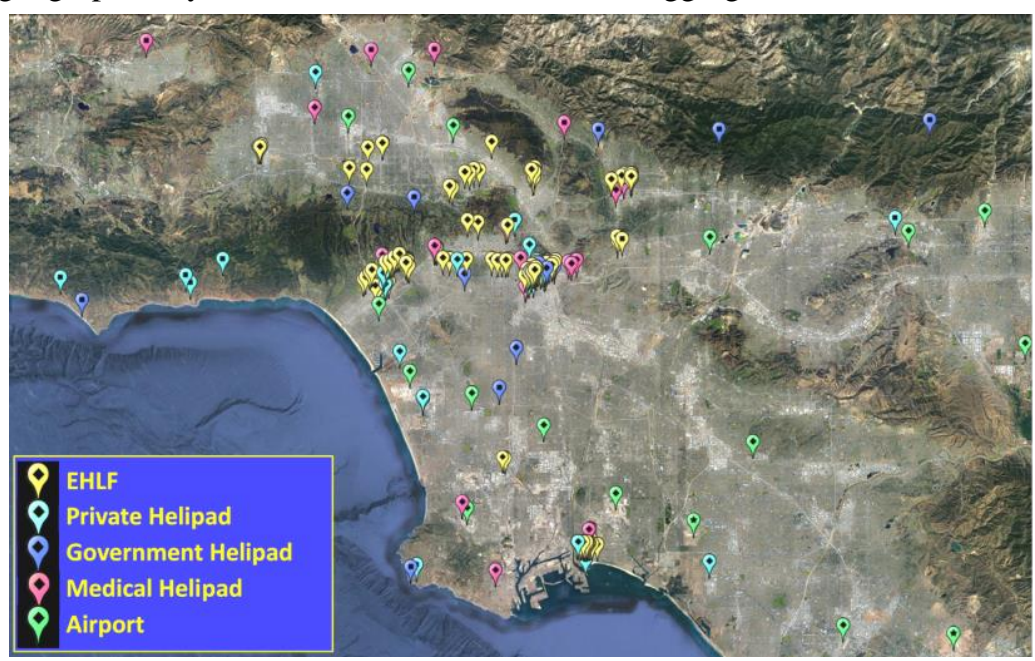

Figure 2. Existing aviation ground infrastructure in L.A. Map @ 2016 Google. Map Data: SIO, NOAA, U.S. Navy, NGA, GEBCO, NSF, USGS.

pronounced in the central Los Angeles CBD where there are over 80 helipads within a two mile radius, but then little to no aviation ground infrastructure in the surrounding communities.

While the high density of available TOLAs in the CBDs may provide ODM Aviation networks with excellent access to ground infrastructure within these high population regions, the surrounding satellite cities and especially the suburban regions of Los Angeles are underserved or not served by existing aviation infrastructure. This indicates that the current distribution of ground infrastructure may support point-to-point flights between city centers, or flights from airports and other isolated origin points into the city centers. However, the poor distribution of TOLAs may limit the demand for ODM daily commuter services or pointto-point services outside these specific corridors.

The poor distribution of TOLAs (which may generally be considered as leading to low TOLA availability) results in three primary operational challenges that may all reduce consumer demand for ODM Aviation services. Table II provides a summary of these impacts.

Table II. Operational challenges for ODM Aviation resulting from low TOLA availability.

\begin{tabular}{|l|l|}
\hline $\begin{array}{c}\text { Operational challenge resulting } \\
\text { from low TOLA availability }\end{array}$ & \multicolumn{1}{c|}{ Description } \\
\hline $\begin{array}{l}\text { Increased first mile/last mile } \\
\text { transportation requirements }\end{array}$ & $\begin{array}{l}\text { Few TOLAs serving a geographic area increases the ground distance some } \\
\text { customers must travel to or from an available facility. This ground transport } \\
\text { leg adds time, complexity and expense to the overall mission. }\end{array}$ \\
\hline $\begin{array}{l}\text { Increased ground and air traffic } \\
\text { congestion }\end{array}$ & $\begin{array}{l}\text { Isolated TOLAs may lead to ground and airspace congestion at those } \\
\text { locations, particularly if aircraft turn-time is slow. }\end{array}$ \\
\hline $\begin{array}{l}\text { Reduced ODM aircraft staging and } \\
\text { deployment capacity }\end{array}$ & $\begin{array}{l}\text { Distributed staging of aircraft is only possible with a high density of TOLA } \\
\text { infrastructure in a geographic area. }\end{array}$ \\
\hline
\end{tabular}




\section{B. Approaches to Increase the Availability of ODM Aviation TOLAs}

In order for ODM Aviation to serve more than a few specific routes in Los Angeles, the availability of TOLAs must be significantly increased in many underserved areas and the EHLFs must be certified for commercial operations. There have been a variety of proposals to increase TOLA availability in metropolitan areas, and each proposal impacts the three challenges presented in Table II differently. Considering these proposals as a whole, two common approaches emerge:

1. Reduce the landing requirements for ODM aircraft through flexible vehicle designs thereby allowing for ODM operations at smaller, less developed TOLAs.

2. Develop new TOLA infrastructure in high demand areas.

Table III presents a listing of potential mitigation approaches to increase TOLA availability that were collected by the authors. These concepts were either presented in literature, introduced at the series of NASA ODM workshops, or discussed by the author with stakeholders in the community. Table III is not intended to present a complete set of potential mitigation approaches, but rather a sampling of those in consideration by the community.

Table III. Potential approaches to increase TOLA availability.

\begin{tabular}{|l|l|}
\hline \multicolumn{1}{|c|}{$\begin{array}{c}\text { Reduce TOLA landing requirements through } \\
\text { flexible vehicles }\end{array}$} & \multicolumn{1}{c|}{ Develop new TOLA infrastructure } \\
\hline Lowerable basket, ladder, or gondola & TOLAs overtop highways, roads or rails \\
\hline Tall landing gear to land overtop parked cars & TOLAs within highway clover leaf clearings \\
\hline Diminished downwash to reduce TOLA size & $\begin{array}{l}\text { TOLAs co-located with gas stations, superstores, or } \\
\text { other geographically well-distributed businesses }\end{array}$ \\
\hline Vehicles certified to land on small footprints & $\begin{array}{l}\text { TOLA development overtop parking lots or on the } \\
\text { top floor of multi-level parking decks }\end{array}$ \\
\hline Vehicles with fast surface turn-time operations & TOLAs on rooftops \\
\hline Vehicles with reduced noise profiles & TOLA development on docks or floating barges \\
\hline $\begin{array}{l}\text { Vehicles capable of landing on a variety of } \\
\text { unimproved surfaces }\end{array}$ &
\end{tabular}

Achieving significantly increased TOLA availability in Los Angeles (or any city for that matter) will likely require investments in a portfolio of these potential mitigation approaches, subject to the unique characteristics of the particular area. Developing more flexible ODM aircraft that reduce the disturbance of landing (noise, downwash, etc.) while allowing for the safe maneuvering of the vehicle in smaller areas (deadman's curve, stability and control, etc.) will be important enablers of developing improved TOLA facilities in communities, or perhaps allowing for offheliport landings at unimproved TOLAs. Supplementing the existing TOLAs with a diverse network of new TOLA infrastructure may also be necessary to create viable and ubiquitous ODM networks.

In order to assess how the various mitigation approaches for TOLA availability outlined in Table III may address this constraint for both nearterm and far-term ODM networks, an infrastructure development investigation was conducted in a region of Los Angeles currently underserved by TOLAs. Figure 3 shades in pink the 101 square mile reference area chosen for this study. There are currently 10 TOLAs in the reference area including three private heliports, three community airports, three EHLFs, and a hospital helipad. The maximum driving distance from within the reference area to reach the closest existing TOLA is 5.5 miles. This trip may take as much as 35 minutes during peak traffic periods.

A majority of the new TOLA infrastructure options proposed in the right hand column of Table III could theoretically be implemented in the reference area. Each of these new TOLA options were investigated in the reference area to determine how many facilities could be developed, the geographic dispersion of these facilities, and the average travel distance required to reach one of these facilities from any possible origin point within the reference area. Table IV displays a summary of these characteristics for the existing scenario and three possible new TOLA scenarios of increasing coverage.

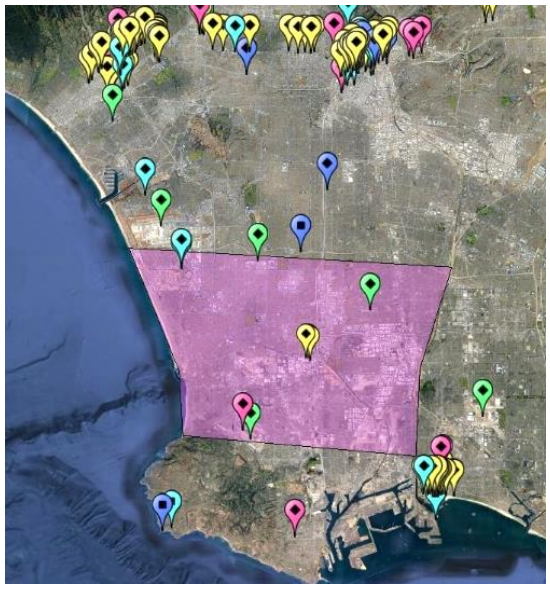

Figure 3. Reference area for new TOLA development investigation. Map () 2016 Google. Map Data: SIO, NOAA, U.S. Navy, NGA, GEBCO, $N S F, U S G S$. 
Table IV. Efficacy of potential approaches to increase TOLA availability in the L.A. case study.

\begin{tabular}{|c|c|c|}
\hline TOLA development concept & $\begin{array}{c}\text { \# of possible locations } \\
\text { in reference area }\end{array}$ & $\begin{array}{c}\text { Maximum distance to } \\
\text { any origin from a TOLA }\end{array}$ \\
\hline Current infrastructure & 10 & 5.5 miles \\
\hline TOLAs co-located with gas stations & 116 & 1.7 miles \\
\hline $\begin{array}{c}\text { TOLAs co-located with 50ft x 50ft } \\
\text { undeveloped surface lots }\end{array}$ & 500 & $1200 \mathrm{ft}$ \\
\hline TOLAs co-located with roadway surfaces & $\sim$ & $100 \mathrm{ft}$ \\
\hline
\end{tabular}

From this study, it was found that co-locating TOLAs with gas stations provided a dramatic improvement in the number of TOLAs and positioned these TOLAs relatively homogenously throughout the reference area (geographically well-distributed). Furthermore, some major roadway intersections hosted up to three gas stations suggesting that these areas could function at higher capacity with coordinated operations between the TOLAs.

The second approach considered was developing TOLAs on currently undeveloped 50ft by 50ft surface lots. This approach raised the number of TOLAs in the 101 square mile reference area to over 500 facilities and reduced the maximum travel distance from an origin to the nearest TOLA to 1200ft. Urban planners frequently consider 400 meters $(\sim 1300 \mathrm{ft})$ to be the target walking distance to public transportation modes that is acceptable by most ablebodied individuals [9], [10]. Therefore, this level of coverage of ground infrastructure would make the ODM Aviation network accessible to a majority of the population in the reference area without the need for first mile and last mile surface transportation modes. Finally, if ODM aircraft had the capability (and appropriate permissions) to alight on the roadway infrastructure, then the first mile/last mile travel distance for ODM Aviation to be on the same order as that for personal or commercial cars.

It should be noted that TOLA construction, approval (including local zoning and FAA approvals), and operational carrying costs were not considered in this initial mitigation proposal review, but rather only the efficacy of such mitigation proposals assuming the TOLAs could be developed and utilized. The next sub-section will review the feasibility of these considered proposals.

\section{Feasibility of Proposed Approaches to Increase the Availability of TOLAs}

The previous section reviewed the degree to which a set of proposed new infrastructure paired with aircraft vertical takeoff and landing capabilities could potentially increase the availability of TOLAs to support an ODM Aviation network. While that analysis assessed the potential maximum geographic distribution of TOLAs that could be achieved though these potential mitigation proposals, it did not assess the overall feasibility of implementing any of those proposals. Implementation factors including public acceptance, local and national regulations, unobstructed approach and departure pathways, construction and operations costs, and customer throughput may inhibit the development of TOLAs in some locations. This sub-section briefly reviews the feasibility of developing TOLAs at the sites evaluated above.

\section{Influence of Aircraft Performance Limitations on TOLA Requirements}

Current helipad design is driven in large part by two major vehicle performance considerations that must be accommodated to provide for the safe takeoff and landing of helicopters. The first performance consideration is the design of approach and landing trajectories in a manner that avoids obstacles and the development of a vortex ring state (commonly referred to as "settling with power") during rotorcraft landing. Vortex ring state is a condition where rotor stall occurs as a helicopter descends vertically into its own downwash. This condition may require multiple hundreds of vertical feet to recover from, and therefore is hazardous if occurring at low altitudes such as during landing. In order to avoid entering a vortex ring state, standard takeoff and landing operations follow sloped trajectories rather than purely vertical paths.

The second helipad design-driving performance consideration is autorotation safety. In an engine-out scenario helicopters may conduct an emergency landing maneuver known as autorotation which converts aircraft potential and kinetic energy into rotor inertia. In order to successfully complete this maneuver, the helicopter must be operating at sufficient velocity or height before the loss of power occurs. On a helicopter height-velocity diagram, such as Figure 4 , a recommended takeoff and landing profile is provided that avoids operation in an unsafe region (often known as the "deadman's curve") where the vehicle has insufficient energy to conduct an autorotation. 
Both of these two performance challenges of helicopter flight therefore placed the need upon historical helipads to support sloped approach and departure trajectories. This need translated to heliport design standards that require specific approach and departure pathways to be certified and maintained clear of obstructions. Current recommendations from the FAA in AC 150/5390-2C on heliport design suggest that heliports have at least two inclined approach and departure paths separated by an angle of at least $135^{\circ}$ [11].

Many of the gas stations and $50 \mathrm{ft}$ by $50 \mathrm{ft}$ surface-level clear areas identified as potential TOLA locations not only have obstructions in the immediate vicinity of the takeoff and landing area, but also have obstructions in neighboring properties. If these obstructions cannot be removed or avoided, then they may prohibit the certification of appropriate approach and departure paths. While the advisory circular is non-binding from an FAA standpoint, many local and state municipalities require in their ordinances or laws that aviation infrastructure be built to these

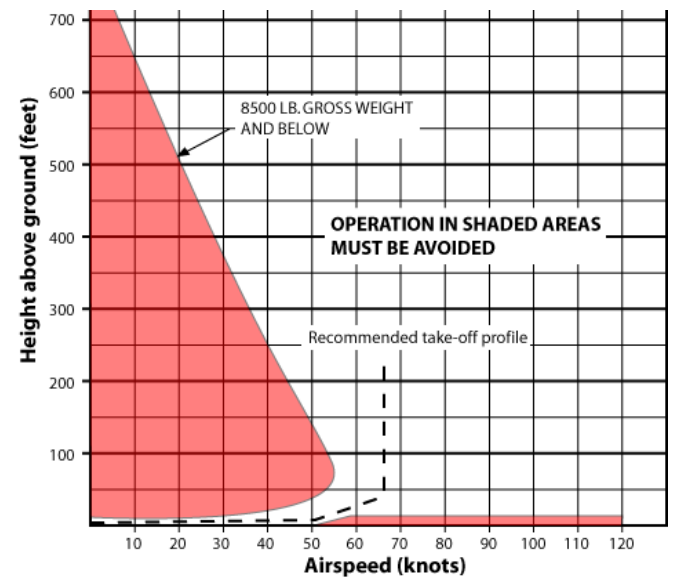

Figure 4. Height-Velocity diagram for Bell 204B helicopter indicating in red the “deadman's" curve. @ BY-SA 3.0. standards, and insurance companies may also require them as a condition of coverage.

While these two performance challenges of flight may have historically hindered the development of helipads in dense urban areas, many proponents of ODM Aviation suggest that new VTOL aircraft could overcome these flight challenges of helicopters. For example, it has been suggested that full-electric, distributed propulsion aircraft do not have a single point engine failure mode and therefore will not have a "deadman's" curve in their height-velocity operating curve. Therefore, such VTOL aircraft may not be required to approach and depart a TOLA with an inclined path [12].

Without this requirement these new aircraft may be capable of safely conducting strictly vertical descent approaches from relatively high altitudes, thereby negating the need for large approach and departure surfaces at low climb angles. The validity of this argument remains to be tested, however, as single point electrical failures and other new failure modes could potentially cause hazard during extensive full-electric aircraft VTOL activities. Furthermore, it is unclear if distributed electric propulsion aircraft will be susceptible to vortex ring state development, and what envelope protections may be necessary to prevent unsafe operating conditions.

Beyond these two primary performance challenges that influence the approach and departure surface size of future TOLAs, the stability of the aircraft and downwash velocity will also directly influence the minimum takeoff and landing surface size. A TOLA must be of sufficient size to safety contain an aircraft operation. For current helicopters, the minimum takeoff and landing surface size must be at least as wide as the diameter of the vehicle rotor, and this surface is surrounded by an additional area (the final approach and takeoff area - FATO) that must be clear of obstructions reaching out to a hundred feet or more in some directions. Current helipad sizing requirements therefore likely prohibit the development of TOLAs with footprints as small as the 50ft by $50 \mathrm{ft}$ dimensions considered.

While future ODM aircraft technologies may provide greater stability and limit the downwash velocity of the vehicles, it is unclear how much the size of TOLAs will be able to be reduced, especially when considering security measures that may be necessary for surface-level facilities

\section{Regulatory Influence on TOLA Development}

Perhaps the most significant near-term challenges for the development of new TOLA infrastructure result from local municipality and state regulations. Municipal regulations vary significantly from locality to locality and would require an ODM operator to conduct a detailed study of each proposed area of operation. To better understand this, a review of the state and local municipality regulations affecting infrastructure development in Los Angeles County was conducted to provide insight into the types of near-term development limitations such regulations may impose.

Table $\mathrm{V}$ presents three regulations that place restrictions on the certification of new TOLAs. These regulations are from the California Public Utilities Code (PUC) and the California Code of Regulations (CCR). These three regulations suggest three important factors for the establishment of new TOLAs.

First, PUC $\$ 21661.5$ empowers local government and citizens to weigh in on the development of any new TOLA with the right to prohibit its development. This implies ODM Aviation operators may have to directly work with each community in which they intend to offer services. 
Secondly, PUC § 21666 requires that every new TOLA has a unique environmental study conducted prior to its approval. While it is unclear how expensive such a study may be, the inclusion of air pollution, noise exposure and surface traffic impact studies appears to suggest a relatively involved study is required.

Finally CCR $\S 3533$ (b) provides a mechanism through which TOLAs could be established for temporary events (such as concerts, games or film festivals), however this process requires specialized approval from CALDOT that involves additional paperwork and levies further operating limitations.

Table V. Regulations that potentially create TOLA certification challenges.

\begin{tabular}{|c|l|}
\hline \multicolumn{1}{|c|}{ Regulation } & \multicolumn{1}{c|}{ Description } \\
\hline PUC $\S 21661.5$ & $\begin{array}{l}\text { City councils and county boards of supervisors (or their designees) must approve } \\
\text { every TOLA in their boundaries }\end{array}$ \\
\hline PUC $\S 21666$ & $\begin{array}{l}\text { Requires every TOLA certification conduct an environmental study that includes } \\
\text { noise, air pollution and ground surface traffic impact, among other aspects }\end{array}$ \\
\hline CCR $\S 3533$ (b) & $\begin{array}{l}\text { Temporary helicopter landings sites are exempt from permitting requirements, } \\
\text { but cannot be used for more than a year and must be granted authorization by } \\
\text { CALDOT (an onerous process in itself) }\end{array}$ \\
\hline
\end{tabular}

Taken as a whole, these three regulations impose significant challenges on the development of new TOLAs. Furthermore, the ability of local authorities to block the development or operation of a TOLA at-will places great uncertainty on where ODM Aviation services will be able to expand to. Considering this factor in particular, TOLAs may have to be constructed on a case-by-case basis following negotiation with the local municipal governments. Developing the dozens to hundreds of TOLAs necessary to provide ubiquitous ODM air transportation for an area as large as the Los Angeles metropolitan region may therefore be a monumental challenge due to regulatory compliance.

The regulatory situation surrounding "off-airport/heliport" landings in areas not certified as aviation facilities is equally challenging. Table VI presents three additional regulations that influence these types of operations.

The first of these regulations explicitly removes the potential for ODM Aviation to land on public roads and provide services with geographic coverage as complete as that of the automobile. While some potential may exist to gain permission from CALDOT for specific operations, this will likely require significant preparatory work and road closures making it unsuitable for standard on-demand operations. Secondly, PUC $§ 21403$ empowers landowners to directly control if and when operations are conducted to or from their property.

PUC $\S 21662.5$ is an especially interesting regulation with profound consequences for ODM operations at noncertified TOLAs. As much as $45 \%$ of the land area within some suburban developments considered in the reference area resided within $1000 \mathrm{ft}$ of a K-12 school. As a result, no aircraft could conduct on-demand operations to an offairport TOLA in a significant proportion of these suburban areas due to the required multi-week approval process. This regulation, which applies to the entire state of California, significantly limits the areas where ODM operations may be conducted without certified TOLAs.

Table VI. Regulations that potentially restrict off-TOLA operations.

\begin{tabular}{|l|l|}
\hline \multicolumn{1}{|c|}{ Regulation } & \multicolumn{1}{c|}{ Description } \\
\hline PUC $\S 21403(\mathrm{~b})$ & Non-emergency, unapproved landing on a public road is not permitted \\
\hline PUC $\S 21403$ & Must have consent of property owner to make a non-emergency landing \\
\hline PUC § 21662.5 & $\begin{array}{l}\text { No helicopter may land or depart within 1000ft of a school maintaining K-12 classes } \\
\text { except at a permitted permanent heliport without completing a strenuous approval } \\
\text { process requiring 15+ days and community hearings at the impacted school(s) }\end{array}$ \\
\hline
\end{tabular}

3. Community Acceptance Influence on TOLA Development

Local communities have significant influence over the ultimate location of TOLAs as a result of PUC $\S 21661.5$ which requires the approval of their elected municipality governments. Considering this, gaining community acceptance for ODM Aviation operations and infrastructure is a key step towards mitigating the overall TOLA availability constraint. Individuals may disapprove of aircraft operations in their community for a variety of reasons including noise, vibrations, privacy, viewshed, emissions, dust and safety concerns. Some of these concerns, such as noise, vibrations and emissions may be lessened by new vehicle technologies. Dust creation may also potentially be eliminated through TOLA design and reduced aircraft downwash. However, privacy, viewshed and safety concerns are more nebulous and may only be possible to address on a case by case basis with individual communities.

Ref. [13] reviewed the legal and regulatory factors surrounding low altitude aviation operations to clarify what rights landowners may have to limit flight over their properties. However, even if pilots are confirmed in the court 
system to have significant overflight privileges, communities may still restrict landing and takeoff operations in their jurisdiction. Therefore, community acceptance is a challenge for the development and operation of ground infrastructure for which there may be no pure technological solution. For this reason, it is especially important that ODM Aviation operators do not prematurely begin operations in the near-term before communities are prepared to accept them. A rushed entry to market without appropriate public relations groundwork could skew public opinion against intra-urban aircraft operations and create inertia behind regulations and laws that stunt the far-term growth of ODM Aviation networks.

\section{Business Influence on TOLA Development}

A final challenge for increasing the availability of TOLAs is the business factors of developing new aviation ground infrastructure. While creating a large, geographically distributed network of TOLAs is likely to increase consumer demand for the service (by reducing first mile/last mile transportation) while simultaneously increasing the network supply of the service (by increasing aircraft throughput capacity in a region), each TOLA also represents a carrying cost to the network. Beyond initial capital investment for construction and certification, TOLAs must be maintained, may require on-site staff or security, and will be subject to taxes, rent, insurance and other potential costs.

Therefore, for financial reasons, the ultimate number of TOLAs in an ODM network will balance the marginal increase in service demand with the marginal increase in carrying costs due to each new facility. For these reasons it is likely that initial operations will rely upon existing single-pad TOLAs and invest in new high-capacity TOLAs in areas of high demand. As the service becomes widely accepted and demand increases, community opposition to TOLAs may be diminished allowing for a less costly expansion of the network to markets in other geographic areas.

\section{Scalability of ODM Networks under Air Traffic Control}

The second prioritized constraint for ODM Aviation concerned whether Air Traffic Control could be scaled or supplemented to support a significant increase in the number and density of low altitude aircraft operations (due to ODM services as well as UAS activities). In other words, how could ATC accommodate significant numbers of new ODM and UAS users, particularly at low altitudes?

While current ATC capacity is sufficient to support near-term ODM operations and early adopter market activities, the system may become overburdened as ODM networks scale. This could create capacity or access limits for ODM aircraft throughput to specific surface-level airspace and ground locations. Considering these factors, while ATC scalability for low altitude operations is not necessarily a near-term constraint, mitigation efforts for ATC scalability should be explored in the short-term as improvements to ATC have historically occurred over long time scales.

The scalability constraint for ATC was decomposed into three separate but related challenges displayed in Table VII. This decomposition allowed for a clearer evaluation of how potential mitigation approaches addressed or failed to address the perceived specific challenges of ODM network scalability under ATC.

Table VII. Challenges for the scalability of ATC to support low altitude aircraft operations.

\begin{tabular}{|c|l}
\hline ODM ATC Scalability Challenge & \multicolumn{1}{c}{ Description } \\
\hline \multirow{3}{*}{$\begin{array}{c}\text { Access to Controlled Airspace } \\
\text { (ATC controller workload) }\end{array}$} & $\begin{array}{l}\text { 92\% of the ODM reference missions in L.A. required entrance into a class } \\
\text { B, C or D surface-level airspace. Such operations require contact with an } \\
\text { air traffic controller. A significant increase in the number of ODM or UAS } \\
\text { flights requesting access to controlled airspace may overwhelm the current } \\
\text { system's capacity preventing entry to these airspace volumes. }\end{array}$ \\
\hline $\begin{array}{c}\text { High Density Operations } \\
\text { (maximum throughput) }\end{array}$ & $\begin{array}{l}\text { Existing radio-frequency communication modes may not provide sufficient } \\
\text { capacity to support high density aircraft operations. Furthermore, ATC } \\
\text { separation standards in controlled airspace may restrict maximum ODM } \\
\text { aircraft throughput. }\end{array}$ \\
\hline \multirow{5}{*}{ Interaction with UAS } & $\begin{array}{l}\text { Helicopters, ODM aircraft and UAS will likely be required to operate } \\
\text { simultaneously in shared airspace over dense metropolitan areas. The FAA } \\
\text { recorded 1200 incidents of UAS close calls with aircraft in 2015, and it is } \\
\text { unclear if the accuracy of spatial and temporal locating technologies are } \\
\text { sufficient to support dense, heterogeneous aircraft and UAS operations. }\end{array}$ \\
\hline
\end{tabular}

The review presented in this section investigates four approaches for low altitude air traffic control proposed by the UAS community to determine if any are readily adaptable to support ATC scalability for ODM Aviation 
operations. It was determined that while each of the four proposed techniques may support ODM operations in airspace not managed by ATC, only one approach addresses operations within actively managed airspace. This approach, which involves expanding and modernizing the current ATC system, would likely only be available as a far-term solution due to the expense and duration of ATC modernization. Furthermore, none of the proposed mitigation techniques explicitly considered low altitude manned aviation, and a shift of focus would be necessary to accommodate both UAS and ODM aircraft.

Considering the limited potential of the proposed UAS ATC mitigation approaches to address the ODM challenge, current-day aircraft operations in proximity to the Los Angeles International Airport were reviewed using twelve months of ASDE-X flight trajectory data. The review found that over $80 \%$ of the operations were commercial flights. These commercial operations physically accessed only $5 \%$ of the available low altitude airspace. ATC, on the other hand, controlled $61 \%$ of the available airspace to support these operations. It should be noted that while commercial aircraft may only have physically accessed $5 \%$ of the airspace, significant volumes of additional airspace are required by ATC to meet the current separation minima around aircraft.

The low utilization of airspace by commercial operators indicated that an opportunity may exist to increase flight density and facilitate ODM aircraft access to surface-level controlled airspace through new aircraft ConOps, air traffic management approaches such as the LAANC system proposed by the FAA for UAS or NASA's UTM program, or reducing separation standards by leveraging advance spatiotemporal vehicle locating and reporting technologies.

\section{A. Current Low Altitude ATC Proposals}

Spurred primarily by the desire to support low altitude UAS operations and integrate UAS into the national airspace system, the aviation community has developed a variety of proposals to address low altitude ATC scalability. While the size and payload of ODM aircraft and UAS are quite different, the actual mission profiles of the vehicles are relatively similar. Therefore, the new technologies and ATC approaches proposed for UAS may be directly applicable, or at least informative, to address this ODM constraint.

Furthermore, while the FAA is not currently considering an airspace restructure to accommodate UAS, significant analysis and development has been conducted by private entities, NASA and the FAA on this subject [14]. As the UAS community is the first mover many years before ODM Aviation, it is likely that ATC and airspace changes to support low altitude ATC scalability will be driven by the UAS community rather than the ODM community. The ODM community should therefore evaluate the proposed mitigations provided in Table VIII and contribute to their development so these approaches may jointly serve the needs of both UAS and ODM aircraft.

While each of these proposed mitigation approaches may provide significant increases in ATC capabilities compared to the current system, they lack specific considerations that will be necessary to support ODM Aviation operations.

First, none of these proposals anticipate a significant increase in the number of manned flights in low altitude airspace, but rather focus primarily on UAS operations. As a result, the aircraft segregation and airspace allocation approaches used generally relegate manned operations to flight above $500 \mathrm{ft}$ AGL and reserve, or at least prioritize, the lower altitude airspace for UAS operations. While UAS operations are not automatically permitted near existing airports in these proposals, ODM aircraft seeking to access new TOLAs, un-towered heliports, or off-heliport landing areas may encounter denial of entry or long wait times under the ATC schemes of these proposals.

Table VIII. Current proposed approaches to low altitude air traffic control for UAS and other operations.

\begin{tabular}{|c|l|}
\hline Proposed Approach & \multicolumn{1}{c|}{ Description } \\
\hline $\begin{array}{c}\text { Airspace Segregation } \\
\text { by Aircraft Capability }\end{array}$ & $\begin{array}{l}\text { Low altitude airspace is segregated, typically through altitude stratification, to permit } \\
\text { aircraft (or UAS) of similar type, equipage and performance capabilities to fly in } \\
\text { common corridors }\end{array}$ \\
\hline $\begin{array}{c}\text { Airspace Allocation to } \\
\text { Requested Operations }\end{array}$ & $\begin{array}{l}\text { Dynamic or static allocation of reserved airspace "zones" are granted to requestors by a } \\
\text { central airspace controller. Only a single operator is allowed in a reserved zone. This } \\
\text { approach is commonly referred to as geofencing }\end{array}$ \\
\hline $\begin{array}{c}3^{\text {rd }} \text { Party Airspace } \\
\text { Service Providers }\end{array}$ & $\begin{array}{l}\text { Traffic separation and route planning is provided by a non-governmental, } 3^{\text {rd }} \text { party } \\
\text { airspace service provider. Approaches to separation and route planning range from pre- } \\
\text { planned, centralized route optimization by the service provider to "free flight" concepts } \\
\text { with communications and real-time deconfliction conducted by on-board software }\end{array}$ \\
\hline $\begin{array}{c}\text { FAA ATC Expansion } \\
\text { and Automation }\end{array}$ & $\begin{array}{l}\text { Expansion and automation of current FAA ATC capabilities (as part of NextGen or } \\
\text { beyond) to manage high density, low altitude operations in controlled airspace }\end{array}$ \\
\hline
\end{tabular}


In order to prevent the lock-in of an ATC system that does not effectively consider the interaction of manned aircraft and UAS in low altitude airspace, the ODM and UAS communities may need to coordinate approaches to handle flight priority and access to airspace or flight corridors, especially in on-demand service situations.

A second gap in the proposed ATC scalability approaches is that some of the approaches may inefficiently use airspace and lead to denial of access in high density ODM or UAS operational scenarios. By allowing for the individual allocation of airspace through geofencing, or designating specific altitude bands that are available only for certain types of aircraft or operations, airspace becomes segmented and unavailable to some operators. The capability to reserve airspace through geofencing (especially if reservation lead times are long) is counter to the needs of an ondemand service. Furthermore, designating large blocks of airspace for only a single operation, or only for a specific type of aircraft, may reduce throughput potential to that airspace and the surface area it covers

While geofencing and airspace stratification may be necessary in the near-term to provide for the safe operation of UAS and manned vehicles, as technologies and experience improve these systems may need to be relaxed to enable the more efficient, simultaneous use of airspace by aircraft in close proximity to other operations.

The final gap evident in the current low-altitude ATC proposals is that except for the FAA ATC expansion proposal, none of the approaches addressed low altitude flights within class B, C, D or E controlled airspace. The reference missions from the Los Angeles case study suggested a significant number of ODM Aviation operations may require access to such surface-level controlled airspace. Figure 5 displays the surface-level controlled airspace in the Los Angeles metropolitan area in yellow. These airspaces cover approximately $43 \%$ of the densely populated metropolitan area (shaded green in the figure).

In order to provide ODM Aviation operations with reliable access to low altitude airspace, additional mitigation efforts should be developed, or the currently proposed approaches enhanced to support ODM operations in low altitude controlled airspace.

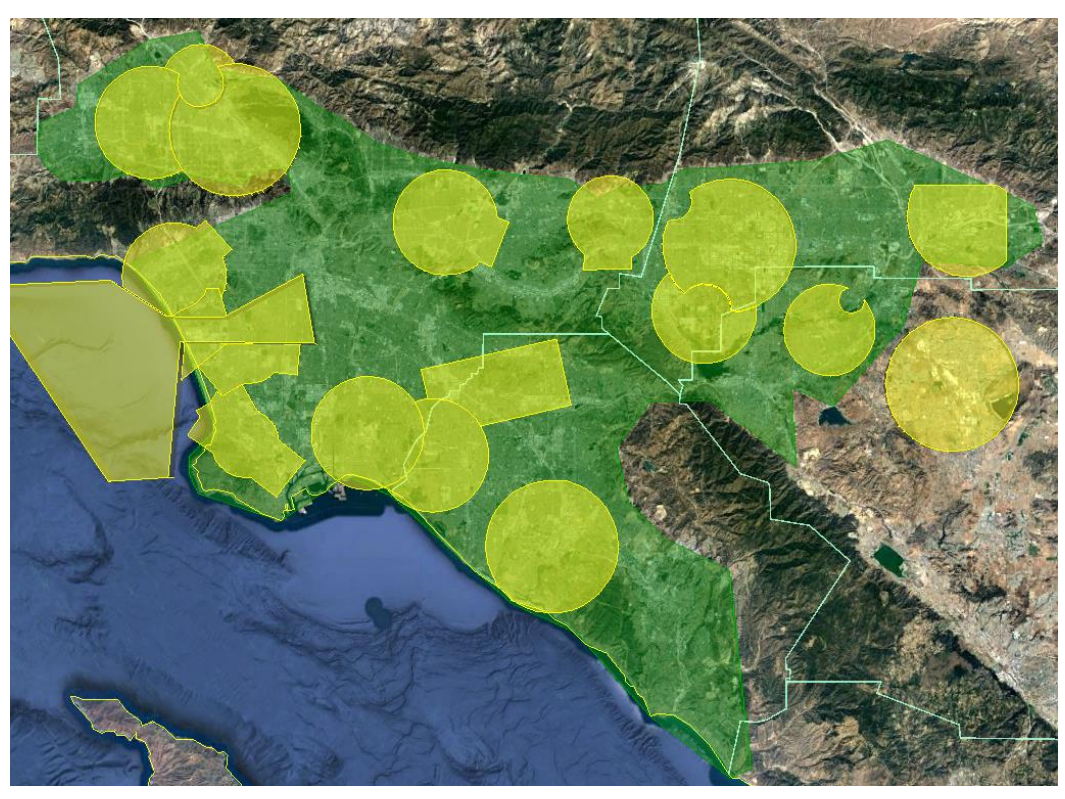

Figure 5. Surface-level controlled airspace (yellow) cover $43 \%$ of the densely populated areas (green) in L.A. Map ( 2016 Google. Map Data: LDEO-Columbia, NSF, NOAA, SIO, U.S. Navy, NGA, GEBCO.

\section{B. Investigation of Current Air Traffic in Low Altitude Controlled Airspace}

To better understand opportunities to improve ATC scalability in low altitude controlled airspace, present-day aircraft operations in the Los Angeles basin were first reviewed. Twelve months of flight tracking data from the Los Angeles International Airport (LAX) was collected and analyzed to identify the flight patterns of general aviation aircraft, helicopters and commercial aircraft. It was anticipated that a review of flight data may reveal trends for each class of operation to inform how a significant number of new ODM flights could be integrated into the airspace.

ASDE-X, or Airport Surface Detection Equipment Model X, is an advanced aircraft surveillance system that is installed at 35 of the busiest airports in the United States. The system uses multiple data sources to provide high quality flight tracking data to air traffic controllers with a maximum update time of 4.65 seconds. The system has a coverage radius of roughly $10 \mathrm{nmi}$ around equipped airports and is commonly recognized as a useful tool to support the analysis of operations in the vicinity of equipped airports.

To support the analysis, ASDE-X flight tracking data from LAX covering the period of April 1, 2015 through March 31, 2016 was evaluated. The data was refined to resolve anomalous data points, discard days with incomplete data sets, and smooth the recorded flight trajectories. The resultant data set contained 203 days of complete flight trajectory data for 536,000 aircraft flights. Figure 6 displays the coverage area of the LAX ASDE-X data. The blue 
circle represents the airport location. The surfacelevel Class D airspace volumes are indicated with dark red while the surface-level Class B airspace volumes are indicated in bright red.

The final 536,000 ASDE-X flight trajectories were aggregated and plotted onto a two-dimensional heat map with axes of latitude and longitude. Since flight trajectories also have a third dimension of altitude, multiple heat maps were created where each one covered a $200 \mathrm{ft}$ altitude slice spanning from 300 $\mathrm{ft}$ AGL (measured from the LAX elevation) up to $12,000 \mathrm{ft}$ AGL. Each cell, or 3D bin, of the heat map was roughly $200 \mathrm{ft}$ by $200 \mathrm{ft}$ in dimension and covered $200 \mathrm{ft}$ of altitude.

Figure 7 and Figure 8 present two altitude slices of the ASDE-X data displaying the annual density of flights near LAX at $700 \mathrm{ft}$ and $1500 \mathrm{ft}$ MSL, respectively. "Hot" airspace cells are indicated in yellow and represent where at least 2 flights per day (FPD) flew; the maximum flight density in a cell was over 400 flights per day. "Cold" airspace cells are indicate in blue and represent where 1 flight per week (FPW) or less was recorded by the radar. Surface level controlled airspace is outlined in green and airport runways are indicated by red bars. Notable aspects of the figures have also been indicated.

The primary takeaway from the air traffic analysis was that there exists highly concentrated corridors of commercial operations off the ends of the runways (on SID and STAR routes) with sparse, distributed General Aviation (GA) and helicopter flights throughout the rest of the region. The GA and helicopter operations concentrate into specific corridors to pass through or around the LAX Class B airspace, but otherwise are far more distributed. Finally, a majority of the evaluated airspace has no commercial flights and few to no GA or helicopter flights over the course of the period analyzed. This suggests that the percent of the airspace being physically utilized for flight may actually be relatively low and it may be possible to add a large number of new ODM flights without dramatically altering current airspace or operations.

A detailed analysis of the ASDE-X radar data revealed that in the coverage area in Los Angeles, only $5 \%$ of the airspace cells below $2500 \mathrm{ft}$ MSL physically contained five or more commercial aircraft flights per year. GA and helicopter flights on the other hand, while accounting for only one fifth as many flights as the commercial aircraft, physically accessed 19\% of the airspace below $2500 \mathrm{ft}$ MSL. Within this same volume, surface-level ATC covered $61 \%$ of the airspace up to $2500 \mathrm{ft}$. While commercial aircraft may only have physically accessed $5 \%$ of the airspace, additional airspace within $1000 \mathrm{ft}$ vertically

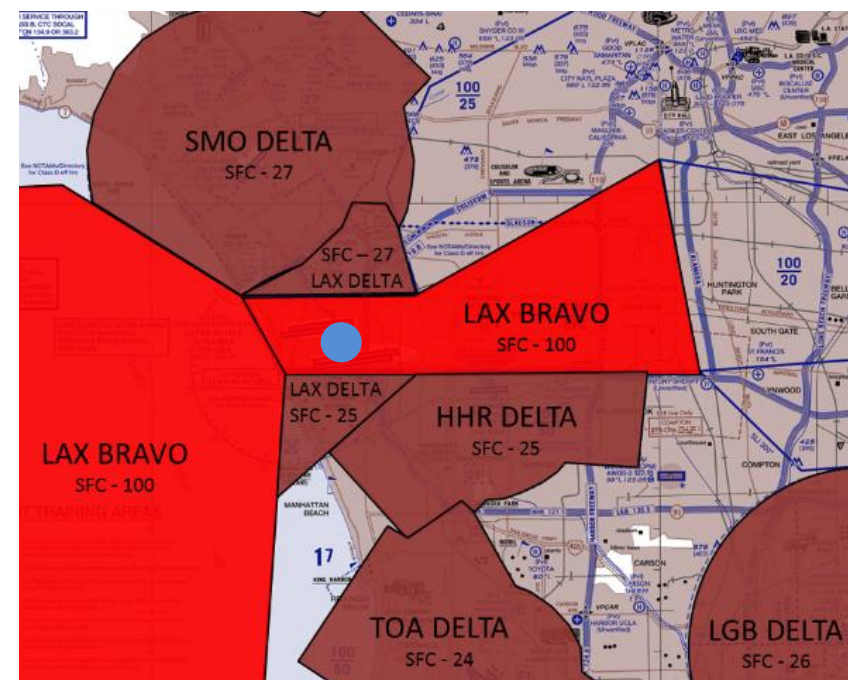

Figure 6. ASDE-X radar coverage with surface-level airspace in red and the radar location indicated in blue.

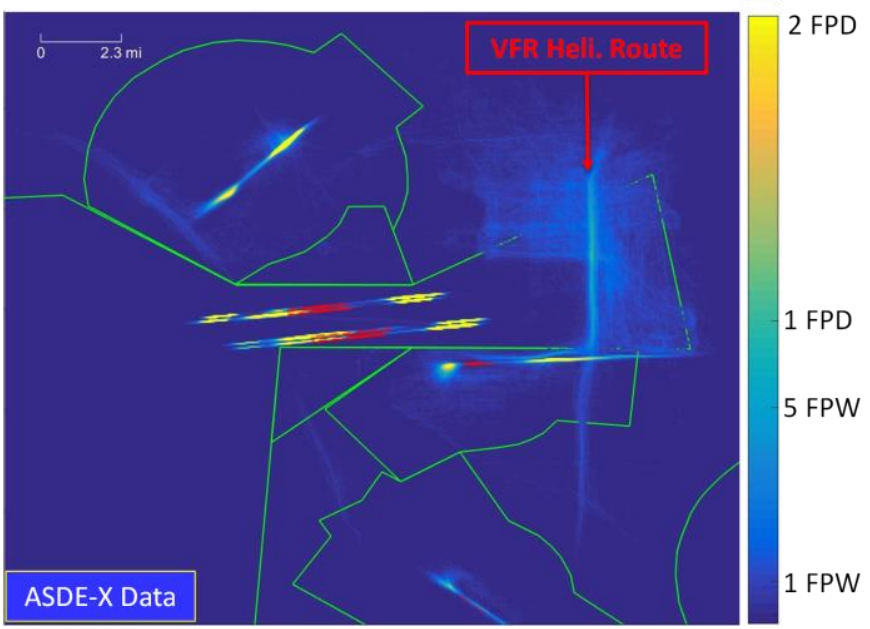

Figure 7. LAX annual flight density heat map for an altitude slide of 700-900ft MSL.

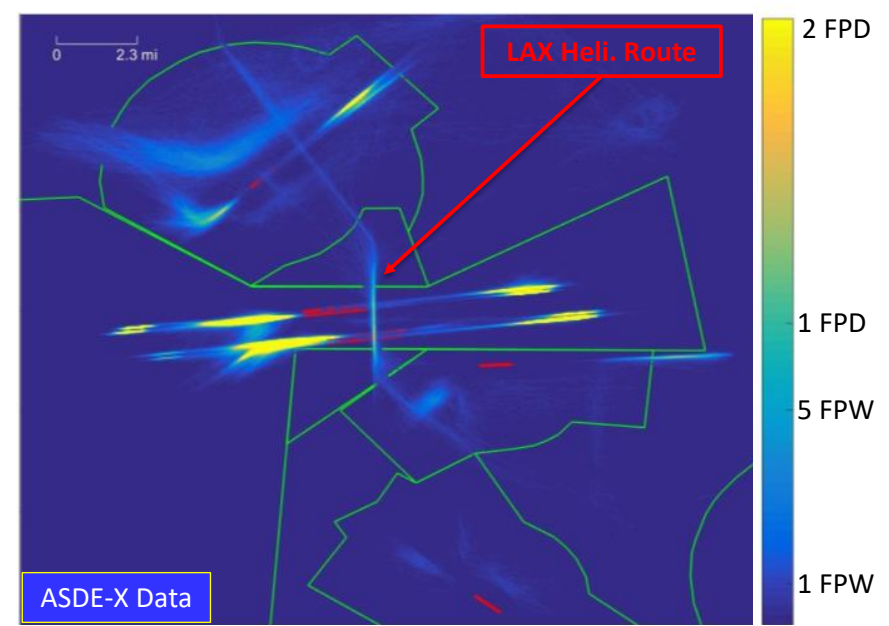

Figure 8. LAX annual flight density heat map for an altitude slide of 1500-1700ft MSL. 
and three statute miles laterally of the aircraft should also be considered as utilized since this airspace is required to provide separation assurance by ATC.

The ASDE-X radar flight track analysis was also conducted in San Francisco, Boston, and New York City. San Francisco and Boston each displayed significantly less GA and helicopter airspace utilization due to the far reduced traffic of this kind in these metropolitan areas. The New York airspace had an even more complex interaction of aircraft and flight paths due to the three major airports in the area and substantial GA and helicopter activities.

\section{Potential Mechanisms to Reduce ATC Workload and Increase Flight Density in Controlled Airspace}

A majority of low-altitude controlled airspace is designed as simple cylindrical volumes centered on the primary airport. These simple geometries often require ATC to manage a larger area than is necessary to protect operations to and from the airport. Providing separation assurance is a workload intensive activity for ATC that relies upon maintaining large separation minima around aircraft resulting in low achievable flight density. Therefore, an opportunity may exist to both reduce ATC workload and increase the achievable density of aircraft operations by allocating airspace differently or reducing the separation minima between aircraft operating in controlled airspace or Instrument Meteorological Conditions (IMC). Ultimately, a safety analysis should be conducted to evaluate how new technologies and airspace allocation approaches could increase the throughput of terminal-area operations while maintaining acceptable levels of safety.

\section{Separation Minima}

The maximum air traffic density that an airspace can support is determined by the separation standard applied to aircraft operations within that airspace. For terminal-area operations in class B airspace, in IMC, or under Instrument Flight Rules (IFR), ATC applies Minimum Radar Separation (MRS) standards which generally require aircraft to be separated laterally by three statute miles and vertically by $1000 \mathrm{ft}$. High-density operations are unlikely to be feasible in airspace where current MRS standards are applied, especially when it is considered that most ODM operations will be occurring within a few thousand feet of the surface thereby limiting the potential to vertically separate these flights.

In Visual Meteorological Conditions (VMC) aircraft pilots may take separation responsibility from ATC and operate at less than MRS with the right-of-way rules from 14 CFR 91.113 to "see and avoid" and "pass well clear" of other aircraft. Pilot-applied visual separation does not set a minimum offset distance laterally or vertically from other aircraft and may therefore support significantly more dense operations than when MRS is in effect. Furthermore, the assumption of separation responsibility by the pilots releases ATC of this workload.

To have pilot-applied visual separation between aircraft in terminal-area controlled airspace, it is required that pilots report and maintain visual contact with all aircraft they must be separated from; air traffic controllers may also apply visual separation standards if they can observe the flights [15]. These conditions may be reasonably met for near-term, infrequent ODM operations, but will become infeasible for numerous ODM aircraft and commercial aircraft operating in close proximity to one another (or during IMC). It should be noted that ATC is also still responsible for maintaining MRS between an aircraft providing self-separation and any other flights in the area that remain flying under ATC-provided separation.

Considering the current state of aircraft separation outlined above, air traffic densities in low altitude controlled airspace may be increased by revising minimum radar separation standards to reflect the accuracy of current-day geolocating systems, or adjusting the ATC ConOps to utilize aircraft self-separation more frequently.

First, high integrity onboard ADS-B and GPS equipage reports aircraft location to a higher degree of temporal and geographic accuracy than the radar systems which the current MRS standards were developed for. A safety analysis may be able to take credit for vehicles equipped with these new technologies and support a reduction of the MRS standards to reflect modern surveillance capabilities. Adjusting the MRS standards may also reduce flight densities in IMC since pilot-applied visual separation is not possible in these conditions.

Second, since ODM aircraft are anticipated to operate at low altitudes more frequently than most current aircraft, it may also be appropriate to consider separation standard reductions based upon the ATC final approach and runway separation minima. On final approach, same runway separation for all helicopters and small aircraft under 12,500 lbs is $3,000 \mathrm{ft}$ [15]. Furthermore, some air shows such as Oshkosh reduce small aircraft lateral separation to $1500 \mathrm{ft}$ by implementing adjusted ConOps and infrastructure [16]. Operations such as Oshkosh may provide a precedent for reduced separation standards for ODM flights in low altitude airspace or in the vicinity of TOLAs.

Third, new ConOps for ODM Aviation ATC could be considered to maximize the flight density and throughput of airspace. For example, "platooning" concepts from automated car and truck research could be applied to ODM Aviation. In such a ConOps, numerous ODM aircraft may group together (on takeoff or in flight), separate from one 
another through visual separation, and then be considered by ATC as a single formation operation and provided with appropriate separation services as a group.

Finally, alternative airspace allocation approaches such as dynamic, fine-scale airspace allocation or the development of Special Flight Rules Areas (SFRAs) show potential to reduce air traffic controller workload by automatically transferring low altitude separation responsibilities to pilots and reducing the area actively managed by controllers. These two approaches are discussed further in the following subsection.

\section{Airspace Allocation}

New approaches to airspace allocation may reduce areas where ODM pilots are required to interface with ATC (thus reducing ATC workload), and create more places where Visual Flight Rules (VFR) using pilot-applied visual separation are standard. The ASDE-X flight trajectory review in Los Angeles indicated that the controlled airspace volumes of the Santa Monica, Torrance and Los Angeles International airports each included sizeable sub-volumes of airspace that were rarely used, not used at specific times, or not used for specific runway configurations.

One potentially beneficial approach to airspace allocation is to redefine the geometry of terminal-area airspace to only include the specific volumes necessary for modern flight procedures (as opposed to defining a simple cylindrical geometry). Reducing the surface-area covered by controlled airspace would enable ODM aircraft to access additional surface-level airspace under VFR without contacting ATC. This approach was previously pursued at select congested airports in the United States, such as Seattle, to reduce the volume of the surface-level controlled airspace while maintaining an equivalent level of safety. Furthermore, the FAA's NextGen Metroplex Airspace Initiative is also investigating airspace redesign around 13 of the nation's busiest airport areas to "improve the efficiency of airspace that affects multiple airports near large metropolitan areas" [17, p. 2]. The downside of individualized airspace redesign, however, is that the airspace and safety analyses required is an expensive and time consuming process.

A second potential airspace allocation approach is to define permanent Special Flight Rules Areas (SFRAs) that allow aircraft to operate inside a sub-volume of controlled airspace under VFR during VMC without being required to contact ATC or use MRS. Numerous SFRAs have been implemented around the country. The Hudson River and Los Angeles International Airport SFRAs provide a model for how these constructs may be used to reduce ATC workload and significantly increase the achievable flight density inside previously controlled airspace. In these two SFRAs, numerous aircraft and helicopters frequently operate within a few hundred feet of each other. While SFRAs may be a viable option where they can be implemented, they are limited in where they may be deployed because of their permanent nature.

A final potential approach to allocate airspace more effectively to support high-density ODM operations is to dynamically allocate airspace at a fine-scale. This concept gives air traffic controllers (or an automated ATC program) the capacity to "open" or "release" a pre-defined airspace sub-volume that is not needed for the current traffic flow configuration. A released airspace volume could be made available for flight to properly equipped aircraft operating under special flight rules. Participating aircraft would likely not be required to contact ATC to fly in the volume. Essentially, fine-scale airspace allocation may be thought of as allowing air traffic controllers to create temporary SFRAs within underutilized areas of controlled airspace for GA, ODM and unmanned vehicles to operation in without increasing the controllers' workload.

As an example of a potential airspace where this concept could be implemented, the volume of airspace to the east of the four LAX runways contains the primary airport approach procedures during the daytime and supports hundreds of flights per day. However, from midnight to 6:30am LAX policies prohibit any non-emergency westbound approach patterns, and this volume of airspace essentially has zero flights during these hours. In dynamic, fine-scale airspace allocation this volume could be released as a temporary SFRA during these hours and be available for ODM operations (assuming they were sufficiently quiet to be acceptable to the community below).

Another precedent for the concept of dynamic, fine-scale airspace allocation is the new FAA Low Altitude Authorization and Notification Capability (LAANC). The LAANC is proposed to create "pre-approved flights zones" in controlled airspace within 5 miles of airports. A UAS operator may query the LAANC online system to automatically be provided or rejected for a clearance to operate within one of these pre-approved zones. The system is proposed to consider the specifications of the flight and the current ATC flow management to assess if the UAS operation represents any potential conflict. This whole approval process is conducted without air traffic controller direct oversight except for edge cases [18].

While operations in both SFRAs and the proposed LAANC system will be conducted under VFR, a more sophisticated air traffic management approach may be required to support high density ODM operations in the farterm. The NASA UTM capability may potentially increase air traffic density by coordinating communication, flight plans, and deconfliction of traffic in low altitude airspace, for example. 


\section{Aircraft Noise and Community Acceptance}

There are an abundance of examples where aircraft noise has prompted various stakeholders to limit or prohibit some or all aircraft and helicopter operations in a region. In a particularly contentious public opinion example, noise generated by low flying helicopters in Los Angeles prompted California representatives to make numerous legislative attempts in Congress to instruct the FAA to create new regulations that reduce helicopter noise in the city. The effort ultimately resulted in the Los Angeles Residential Helicopter Noise Relief Act of 2013 [19]. The final version of the law did not strictly prohibit low altitude operations outright, but prompted the FAA to implement voluntary measures for Los Angeles operators to reduce noise [20].

Airports themselves have also frequently been the focus of aircraft noise debates. Within Los Angeles, the Santa Monica Airport has been under pressure from the Santa Monica City Council and citizens for multiple decades due to the high volume of flights in and out of the airport in close proximity to the public [21]. These local community groups have reduced Santa Monica's hours of operation, excluded some aircraft and operations all together, and are in a legal battle with the FAA to permanently shut down the airport (which the FAA recently agreed to allow in 2029). Table IX displays a set of aircraft and helicopter operating restrictions for three major airports in Los Angeles that resulted from noise considerations.

Table IX. Operational restrictions due to noise at major Los Angeles Airports.

\begin{tabular}{|c|c|l|}
\hline Airport & Vehicle Type & Restriction \\
\hline $\begin{array}{c}\text { Los Angeles } \\
\text { International (LAX) }\end{array}$ & Aircraft & Westerly departure and arrival required between 2400 and 0630 hours \\
\cline { 2 - 3 } & Helicopters & All operations prohibited between 2200 and 0700 \\
\hline $\begin{array}{c}\text { Santa Monica } \\
\text { (SMO) }\end{array}$ & Aircraft & No takeoffs between 2300 and 0700 hours \\
\cline { 2 - 3 } & Helicopters & $\begin{array}{l}\text { May not be used "as a base for any operation involving the substantial } \\
\text { use of helicopters" }\end{array}$ \\
\hline \multirow{2}{*}{ Van Nuys (VNY) } & Aircraft & No takeoffs between 2300 and 0700 if estimated noise level is >74 dBA \\
\cline { 2 - 3 } & Helicopters & No restrictions \\
\hline
\end{tabular}

In a similar vein, the implementation of new, high-precision RNAV departure flight trajectories from Boston Logan Airport has substantially increased the frequency of which some landowners' properties are overflown exposing them to increased noise. This has resulted in unprecedented public resistance to the implementation of the new ATM technology and led to attempted congressional and legal action to prohibit the implementation of RNAV routes at Logan airport [22], [23].

While a litany of additional examples could be presented, the key takeaway is that aircraft noise generation at low altitudes, especially during takeoff and landings, has frequently resulted in public action that imposed restrictions on the operations. Furthermore, it appears that there may be a changing basis of community noise acceptance. For example, although some communities previously tolerated much more severe aircraft noise, current operations and technologies have reduced aircraft noise and the communities will no longer tolerate a return to previous levels. This indicates that there is unlikely to exist a threshold decibel level below which an aircraft will automatically be acceptable to communities.

Ref. [13] reviews how nuisance, trespass, government takings and a variety of other legal mechanisms may potentially restrict low altitude flight due to noise concerns. Figure 9 displays the wide variety of regulatory pathways through which aircraft noise may result in operational restrictions. It should be noted that there are numerous stakeholders involved in this process, many of them elected officials or subordinate to elected officials, who have parallel pathways to impact aircraft operations. As a result, ODM Aviation may have to work with each of these stakeholders, or reduce the impact of aircraft noise on the public itself in order to mitigate this constraint.

\section{A. Current Approaches to Aviation Noise Mitigation}

As a challenge in the aviation community that existed long before ODM Aviation, there are currently a variety of approaches to help mitigate aircraft noise. First, the FAA responds to noise complaints for aircraft or helicopter operations at low altitudes by working with airports to create noise sensitive approach and departure routes, limit airport hours of operation, or exclude some vehicles or operations from an airport [24].

Beyond noise generation regulations levied on the vehicles, voluntary or temporary noise reduction measures are common mechanisms employed to reduce the noise impacts of flight without the need for regulation. The FAA frequently creates Temporary Flight Restriction (TFR) areas around special public events (such as concerts or sporting events) that prohibit unauthorized low altitude flight in the area for noise reduction and safety purposes. The FAA has 


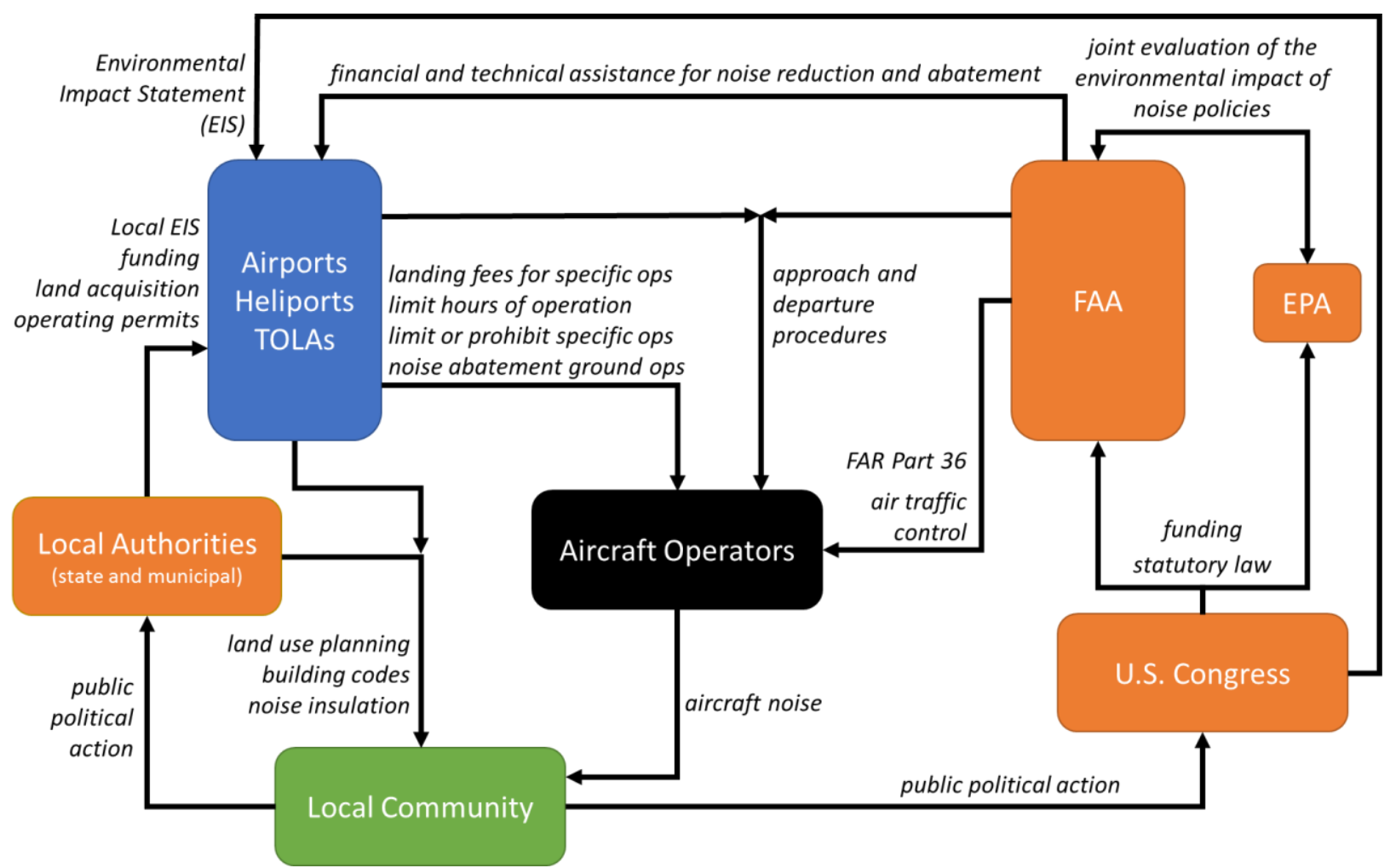

Figure 9. Regulatory pathways through which aircraft noise may result in operational restrictions for aircraft operators. Image developed from information in the FAA Airport Compliance Manual [28] and the 1976 Aviation Noise Abatement Policy III.3.a-e.

also created voluntary helicopter routes, airport transition routes, and VFR flyways that reduce the impact of aircraft noise by concentrating flights over less noise sensitive areas such as highways or industrial parks.

Furthermore, the FAA empowers airports to modify low altitude approach and departure paths for noise abatement purposes through the FAA Airport Noise Program, and asks pilots to adhere to low noise operational recommendations such as those outlined in the Helicopter Association International (HAI) Fly Neighborly Guide [25]. Finally, technological innovations in engine design, acoustic liners, airframe integration and numerous other components have steadily reduced the noise signatures of large aircraft [26].

\section{B. Potential Noise Mitigation Opportunities for ODM Aviation}

Aircraft noise is a complex specialty field of aviation with numerous areas of active research. The purpose of this section is not to delve into the detail of mechanisms to reduce bystander annoyance to aircraft generated noise, but rather to illuminate a few opportunities unique to ODM aircraft that show promise to achieve this goal.

The impact of aircraft noise can be mitigated through two fundamental approaches that may be generally considered as new noise reducing technologies and operations:

1. Technologies: Develop and implement new aircraft technologies that either reduce the source noise emissions from the vehicle, or reduce the annoyance of the noise generated to bystanders on the ground.

2. Operations: Operate the vehicle in a manner such that it either produces less total noise, or such that the noise is emitted in a location or way that causes less annoyance to bystanders on the ground.

A significant amount of interest and excitement has been expressed by the ODM community concerning the potential for new technologies incorporated in ODM aircraft to significantly reduce total noise emissions. The recent Uber white paper on ODM Aviation provides a significant amount of detail on various noise metrics for aviation, quantitative noise goals for ODM aircraft (expressed with these metrics), and the proposed technological means by which to reach them [27]. Table $\mathrm{X}$ displays a summary of the new technology-based mitigation proposals from this white paper as well as other authors. 
Table X. Technology-based ODM aircraft noise reduction proposals.

\begin{tabular}{|c|c|}
\hline Technology & Description \\
\hline Electric Motors & $\begin{array}{l}\text { Replacing piston or turbine aircraft engines with electric motors removes most mechanical, } \\
\text { combustion and exhaust noise sources. Furthermore, electric motor power density is scale } \\
\text { invariant, therefore } 1-2 \text { passenger aircraft may be developed with significantly reduced } \\
\text { takeoff weight reducing thrust and lift and drag requirements resulting in lower noise } \\
\text { generation. Finally, and most significantly, electric propeller tip speeds may be up to } 50 \% \\
\text { lower than helicopter rotor tip speeds dramatically reducing noise but maintaining efficiency }\end{array}$ \\
\hline $\begin{array}{l}\text { Distributed } \\
\text { Propulsion }\end{array}$ & $\begin{array}{l}\text { Aircraft utilizing small, distributed electric propulsors are able to achieve comparative } \\
\text { vehicle performance to helicopters while capturing a variety of acoustic benefits. The small } \\
\text { propellers may be operated with slower tip speeds (reducing noise) and at higher RPM to } \\
\text { avoid low-frequency noise generation. It should be noted that while high-frequency noise is } \\
\text { rapidly attenuated by the atmosphere as compared to low-frequency noise, it is more } \\
\text { disagreeable to bystanders at close range. Finally, some propellers may be de-powered (and } \\
\text { potentially folded) during cruise to reduce noise generation. }\end{array}$ \\
\hline $\begin{array}{l}\text { Frequency } \\
\text { Spectrum } \\
\text { Spreading }\end{array}$ & $\begin{array}{l}\text { On-going research by NASA is investigating if operating distributed propulsors at slightly } \\
\text { different speeds may spread the emitted frequency spectrum in a manner that reduces the } \\
\text { perceive noise annoyance of bystanders. }\end{array}$ \\
\hline $\begin{array}{l}\text { Tiltrotor, Fixed } \\
\text { Wing Aircraft }\end{array}$ & $\begin{array}{l}\text { Tiltrotor capabilities enable VTOL while avoiding edgewise flow over the rotors during } \\
\text { forward flight (as the vehicle cruises in a fixed-wing configuration). This reduces required } \\
\text { rotor speed and reduces noise. Cruise in a fixed-wing configuration also reduces thrust } \\
\text { requirements compared to vertical lift configuration further lowering noise. }\end{array}$ \\
\hline
\end{tabular}

In addition to the potential benefits of these new technologies, performance characteristics unique to some of the new ODM aircraft designs may allow them to be operated in ways that also significantly reduce bystander noise exposure. For example, the HAI Fly Neighborly Guide recommends that helicopters utilize takeoff and descent profiles that are as steep as practicable in order to limit low overflight of neighboring properties and bystanders. While helicopters have typically avoided extended vertical (or extremely steep) ascent and descent profiles due to vortex ring state (settling with power) concerns and autorotation safety, new distributed electric propulsion ODM aircraft may be able to execute these maneuvers safely.

Table XI displays a set of operations to reduce noise that are currently recommended for helicopters that new ODM aircraft and operators may be able to execute more effectively.

Table XI. Noise reduction operations enhanced by potential ODM aircraft capabilities.

\begin{tabular}{|c|l|}
\hline $\begin{array}{c}\text { Operation } \\
\text { Attribute }\end{array}$ & \multicolumn{1}{c|}{ Description } \\
\hline $\begin{array}{c}\text { Cruise at Higher } \\
\text { Altitude }\end{array}$ & $\begin{array}{l}\text { Due to their higher anticipated cruising velocity compared to helicopters, the relative } \\
\text { velocity differential between ODM aircraft and fixed-wing aircraft operating at mid to high } \\
\text { altitudes over metropolitan areas will be reduced. As a result, ODM aircraft may be } \\
\text { approved by ATC to operate in higher altitude, controlled airspace above many metropolitan } \\
\text { regions reducing their ground noise signature. In contrast, the lower reaches of these } \\
\text { airspaces are typically considered as maximum altitude ceilings for helicopter operations. }\end{array}$ \\
\hline $\begin{array}{c}\text { Extended VTOL } \\
\text { Ascent and } \\
\text { Descent }\end{array}$ & $\begin{array}{l}\text { If ODM aircraft with DEP do not exhibit vortex ring state susceptibility during rapid } \\
\text { descent, then these vehicles may be able to operate true vertical ascent and descent profiles } \\
\text { reducing low altitude overflight near TOLAs. }\end{array}$ \\
\hline $\begin{array}{c}\text { Avoid Impulsive } \\
\text { Noise Generation }\end{array}$ & $\begin{array}{l}\text { Tiltrotor ODM aircraft are likely to avoid impulsive noise generation (blade slap) during } \\
\text { sharp maneuvers or high speed descent if they operate in a fixed-wing configuration for } \\
\text { these mission segments. }\end{array}$ \\
\hline Avoid Noise- & $\begin{array}{l}\text { While many current helicopter charter flights operate for tourism purposes and frequent } \\
\text { populated areas or iconic structures at low altitudes, ODM missions are generally for } \\
\text { transportation and may be routed to avoid these areas. Furthermore, aircraft may engage in } \\
\text { "ambient noise masking" by flying along routes of significant ground noise generation such } \\
\text { as highways or industrial areas [29]. }\end{array}$ \\
\hline
\end{tabular}




\section{Conclusion}

Three key constraints were identified by Ref. [5] that may impact the development, implementation or operation of ODM Aviation networks in the near or far-term. These constraints concerned the availability of ground infrastructure, the capacity of air traffic control to manage significantly increased flight densities at low altitude, and the local community's acceptance of noise generated by ODM aircraft. The aim of this research question was to compile a listing of proposed mitigation approaches, evaluate the potential of these approaches to address these three prioritized constraints, and reveal challenges that were not sufficiently mitigated by the current proposals and represented areas requiring future investigation.

To assess the near-term and far-term efficacy of proposed mitigation approaches, the impact of each approach was reviewed regardless of its implementation feasibility. Then, separately, the implementation feasibility of each proposal in terms of cost, community acceptance, technical feasibility and interaction/interfacing with current systems, among other factors, was also assessed. The resulting findings suggested that while effective mitigation approaches appear to exist for all three constraints, the slow rate of regulatory response as well as community acceptance and perception factors may limit the timely implementation or full effectiveness of many of the mitigation approaches.

In terms of ground infrastructure availability, although there are numerous proposed mitigation techniques that show potential to increase the availability of TOLAs in a geographic area, the implementation of a majority of the techniques is hampered by aircraft performance, municipality and state regulations, community acceptance, or business challenges. New technologies, especially electric aviation, show promise to reduce or overcome the aircraft performance and community acceptance challenges of developing new TOLAs. However, existing regulations by and large currently prevent aircraft from landing outside official, certified TOLAs and require a relatively tedious process to approve the construction and use of a new facility. It is anticipated that community acceptance, largely related to aircraft noise, is likely to be the greatest factor limiting the TOLA availability mitigation approaches.

With respect to the low altitude ATC scalability constraint, this research suggested that none of the four currently proposed low altitude air traffic control schemes for UAS sufficiently met the needs of ODM Aviation networks. Primary issues with these approaches included the focus of these new systems on UAS operations, the inefficient use of airspace through geofencing and attitude stratification, a lack of coordination with current ATC, or an unacceptably long anticipated development and implementation period.

Considering these limitations of the proposed mitigation approaches, the current-day usage patterns of airspace in proximity to the Los Angeles International Airport was reviewed using twelve months of ASDE-X flight trajectory tracking data. The review found that over $80 \%$ of operations in the study were commercial flights that physically utilized only 5\% of the available low altitude airspace. ATC, on the other hand, controlled $61 \%$ of the available airspace to support these operations. The low utilization of airspace indicated that opportunities existed to increase flight density and ODM Aviation access to surface-level controlled airspace through new airspace allocation approaches and separation minima reductions. Current efforts by the FAA through the LAANC program and NASA through the UTM program may therefore represent promising mitigation approaches for this constraint.

Finally, aircraft noise and community acceptance was found to be one of the most significant near-term constraints for ODM Aviation operations. Noise emissions from aircraft and helicopters have historically been the most protested community impact of airports. Such public action has frequently placed pressure on regulatory authorities and government entities to limit or prohibit some aviation operations. As a result, aircraft noise from ODM aircraft was anticipated to indirectly influence the location and operation of TOLAs, the type of aircraft that may be used, and the market demand for ODM Aviation services.

Two categories of potential noise mitigation techniques were explored in this paper. First, technology-based mitigations including electric motors, distributed propulsion, frequency spectrum spreading, and tiltrotor configurations were reviewed. These technologies were found to represent a noise reduction potential over current helicopters, especially through rotor tip speed reductions feasible with electric motors. Furthermore, these technologies increased the effectiveness of the second category of noise reduction techniques referred to as operational-based mitigations. Due to unique aircraft performance capabilities, new ODM aircraft may be able to fly at higher cruise altitudes, conduct extended vertical ascents and descents into and out of TOLAs, avoid impulsive noise generation, and bypass noise sensitive communities. These operational-based mitigation techniques have the potential to further reduce the impact of aircraft noise to bystanders on the ground, however it is unclear if the level of noise reduction will enable wide-spread community acceptance. 


\section{Acknowledgments}

This material is based upon work supported by the National Aeronautics and Space Administration under Grant Number NNX14AT14H issued through the NASA Education Aeronautics Scholarship Program and contract NNL16AA58T.

\section{References}

[1] M. D. Moore, "Concept of Operations for Highly Autonomous Electric Zip Aviation," in 12th AIAA Aviation Technology, Integration, and Operations (ATIO) Conference, 2012, no. September, pp. 1-15.

[2] M. D. Moore and W. J. Fredericks, "Misconceptions of Electric Aircraft and their Emerging Aviation Markets," in 52nd Aerospace Sciences Meeting, 2014, no. January, pp. 1-17.

[3] M. Kreimeier, D. Gottschalk, and E. Stumpf, "Economical assessment of air mobility on demand concepts with focus on Germany," in 16th AIAA Aviation Technology, Integration, and Operations Conference, 2016.

[4] A. Harish, C. Perron, D. Bavaro, J. Ahuja, M. Ozcan, C. Y. Justin, S. I. Briceno, B. J. German, and D. Mavris, "Economics of Advanced Thin-Haul Concepts and Operations," in 16th AIAA Aviation Technology, Integration, and Operations Conference, 2016, no. June.

[5] P. D. Vascik and R. J. Hansman, "Constraint Identification in On-Demand Mobility for Aviation through an Exploratory Case Study of Los Angeles," in 17th AIAA Aviation Technology, Integration, and Operations Conference, 2017.

[6] Federal Aviation Administration, “Los Angeles Helicopter Noise Initiative,” Washington, DC, 2013.

[7] City of Los Angeles, “Sec. 57.4705.4 Emergency Helicopter Landing Facility,” Los Angeles Municipal Code, 2013. [Online]. Available: http://clkrep.lacity.org/onlinedocs/2013/13-0359_ord_182822.pdf.

[8] Office of the Fire Marshal, "Los Angeles Fire Department Requirement No. 10,” 2014. [Online]. Available: http://www.lafd.org/sites/default/files/pdf_files/EHLF-Reg10.pdf. [Accessed: 01-May-2016].

[9] Transit Cooperative Research Program, Transit Capacity and Quality of Service Manual, 3rd ed. Washington, DC: Transportation Research Board, 2013.

[10] M. Iacono, K. J. Krizek, and A. El-Geneidy, “Access to Destinations: How Close is Close Enough? Estimating Accurate Distance Decay Functions for Multiple Modes and Different Purposes,” St. Paul, MINN., 2008.

[11] Federal Aviation Administration, “AC 150/5390-2C: Heliport Design,” Department of Transportation, Washington, DC, 2012.

[12] W. J. Fredericks, "Impact of Operational Requirements on Intra-Urban VTOL Conceptual Design [ORAL PRESENTATION]," in 16th AIAA Aviation Technology, Integration, and Operations Conference, 2016.

[13] P. D. Vascik, "Systems-Level Analysis of On Demand Mobility for Aviation," Massachusetts Institute of Technology, 2017.

[14] B. Carey, "For Now, FAA is not Considering Airspace Changes for Drones," AIN Online, 2016. [Online]. Available: http://www.ainonline.com/aviation-news/aerospace/2016-05-03/now-faa-not-considering-airspace-changes-drones. [Accessed: 12-Nov-2016].

[15] Federal Aviation Administration, "JO 7110.65W: Air Traffic Control.” U.S. Department of Transportation, Washington, DC, 2015.

[16] Federal Aviation Administration, "JO 7110.50A: Requesting a letter of authorization for reduced air traffic control separation standards at recurring air shows or fly-ins." Department of Transportation, Washington, DC, 2011.

[17] C. L. Scovel, "FAA's Progress and Challenges in Advancing the Next Generation Air Transportation System," Washington, DC, 2013.

[18] Federal Aviation Administration, "Low Altitude Authorization and Notification Capability (LAANC) Concept of Operations," 2017. [Online]. Available: https://faaco.faa.gov/index.cfm/attachment/download/75780. [Accessed: 19Apr-2017].

[19] A. B. Schiff, H.R.456 - Los Angeles Residential Helicopter Noise Relief Act of 2013. U.S. Congress, 2013.

[20] Federal Aviation Administration, "Significant Progress Report on the Los Angeles Helicopter Noise Initiative," Washington, DC, 2015. 
[21] D. Weikel, "Santa Monica council votes to close the city’s airport by July 2018," Los Angeles Times, Los Angeles, CA, 24-Aug-2016.

[22] M. Deehan, “U.S. Rep. Steve Lynch in dogfight with FAA over Logan airport route changes,” WGBH News, 2015. [Online]. Available: http://news.wgbh.org/post/us-rep-steve-lynch-dogfight-faa-over-logan-airport-route-changes. [Accessed: 09-Oct-2016].

[23] P. Burton, "Massport, FAA take steps to reduce aircraft noise in Boston area," CBS Boston, 2016. [Online]. Available: http://boston.cbslocal.com/2016/10/07/massport-faa-logan-airport-milton-airplane-noise/. [Accessed: 09-Oct-2016].

[24] Los Angeles World Airports, "Aircraft Noise Abatement Operating Procedures and Restrictions," in LAX Rules and Regulations, no. September, Los Angeles, CA, 2010.

[25] C. Cox and J. Leverton, "Fly Neighborly Guide," 2016. [Online]. Available: https://www.rotor.org/Operations/FlyNeighborly/FlyNeighborlyGuide.aspx.

[26] L. Leylekian, M. Lebrun, and P. Lempereur, “An Overview of Aircraft Noise Reduction Technologies,” AerospaceLab, vol. 1, no. 7, pp. 1-15, 2014.

[27] J. Holden and N. Goel, "Fast-Forwarding to a Future of On-Demand Urban Air Transportation," San Francisco, CA, 2016.

[28] Federal Aviation Administration, “Airport Noise and Access Restrictions," in FAA Airport Compliance Manual. Order 5190.6B, 1st ed., Washington, DC: Department of Transportation, 2009.

[29] L. Jensen, J. Thomas, C. Brooks, M. Brenner, and R. J. Hansman, “Analytical Approach for Quantifying Noise from Advanced Operational Procedures," in Twelfth USA/Europe Air Traffic Management Research and Development Seminar, 2017. 